\title{
Optimal Modeling of Energy Storage System
}

\author{
Asmae Berrada and Khalid Loudiyi
}

\begin{abstract}
The variability of solar and wind energy generation presents significant grid integration challenges especially in the operation of power systems. The optimal use of energy storage system may be a viable solution to control and match the power generation to the load profile. This paper proposes a method to identify the optimum daily operational strategy of a storage system. An hourly optimization problem was formulated for this purpose to maximize the economic gain of a wind farm considering the market price and the main operational restrictions of the hybrid energy system. This method is also suitable for other energy resources and energy storage technologies. Another prominent issue facing renewable energy farms is the proper sizing of the energy storage system. A method to optimize the size of the storage system with respect to the net present cost (NPC), while meeting the service requirement is also proposed. Case studies are presented to verify the effectiveness of these models.
\end{abstract}

Index Terms-Energy storage modeling, otptimal operation, scheduling, sizing.

\section{INTRODUCTION}

The penetration of renewable energy has increased, and will continue to grow in popularity as it is clean and domestic energy sources. Yet, renewable energy sources will become widespread due to the world current geopolitical situation, climate change and social challenges. Countries are struggling to achieve energy independence for the sake of their economic well-being and have a desire to not import energy resources such as oil from other countries. In addition, social challenges include the progressive depletion of fossil fuel energy sources while the demand of energy is growing rapidity

Fluctuations in power production make it difficult for renewable power plants to compete in the electricity markets. A viable solution that provides the flexibility for smoothing the solar/wind power is the utilization of energy storage devices. The development and monitoring of energy storage systems are important matters for the future smart grid. In order for renewable energy to become an attractive alternative to fossil fuel, both the hardware and the software infrastructure should be developed. The hardware includes solar/wind technologies, energy storage systems and an improved electric grid. The role of the hardware is to ensure energy generation and transmission.

The software, on the other hand, implements intelligent decisions to allocate the energy captured, and plan the

Manuscript received May 28, 2014; revised August 29, 2014. The research leading to these results has received funding from the European Union Seventh Framework Programme (FP7/2007-2013) under grant agreement no. 608593 (EuroSunMed)

Asmae Berrada is with Al Akhawayn University, Morocco (e-mail: k.loudiyi@aui.ma). quantity to supply in the future.

Eventually, the increased adoption of renewable energy as a domestic energy contributor will depend on the cost effectiveness of the clean-energy in comparison to other energy resources.

Significant research studies on energy storage modeling have been reported recently. Some papers discussed the operation scheduling problem for different hybrid energy system [1]-[5]. The optimal sizing and operation of energy storage have been addressed in [6], [7]. Other papers, studied the optimum sizing problem for different energy storage working conditions and taking the economic benefits as the basic consideration [8]-[16]. Chakraborty [17] presented a new method to optimize the size of energy storage combined with a thermal power system. An economic life cycle cost analysis of the energy storage was used in the formulation of the problem. Brekken et al. [18] investigated an optimization design and control of energy storage to reduce the cost of integration related to reserve requirement and increase the wind plant outputs. The author in [19] proposed a methodology for sizing an energy storage system using wind power forecast uncertainty.

Li [20] presented an optimization algorithm employing an iterative scheme to identify the optimum size for a stand-alone micro-grid power system.

Therefore, the study about energy storage system operation control and sizing has become a topic of interest in several literature. Hence, new methods for the operation scheduling and sizing of energy storage in a market system has been developed in this paper. This work aims also to discuss and verify an application of the proposed methods on a case-study.

This paper is organized as follows. Section II presents the different models that will be discussed in this work. In Section III, a method to identify the optimum daily operational strategy is described. Section IV presents the storage sizing models. Finally, Section V brings to a close the paper.

\section{ENERGy Storage Modeling}

There are two kinds of decisions a renewable energy farm operator should make. The first one is how to allocate energy and make energy commitments on the electricity market. The energy allocation decision depends on three sources of uncertainty: energy prices, wind speed or wind energy supply, and energy demand. After modeling these three sources of uncertainty, an optimization method will be used to address the allocation problem. The second decision is related to which storage technologies to invest in, and with what properties. Various storage technologies have the advantage that their capacity is scalable. Therefore, the optimal storage 
sizing is considered another issue.

\section{OPTIMAL SCHEDULING STRATEGY}

The operations of energy storage system will be modeled as an optimization problem. In this category, several researches generally investigate the problem in a window of twenty four hours and the decisions are made on hourly basis. It is common practice to perform the optimization model for only one day in advance because the accuracy of the electricity price forecast degrades significantly throughout the week. Therefore, modeling the operation of a storage system for a week in advance does not make much sense. This work will also follow the same time frame and window.

An optimization problem was formulated for this purpose to maximize the economic gain of the renewable energy farm considering the market price and the main operational restrictions of the hybrid energy system in 24 hourly periods. The solution of this problem provides an operational strategy to be followed by the renewable energy operator during the next hours.

\section{A. Modeling Assumptions}

\section{1) Assumption 1: electricity market}

All energy transactions will take place in one market: the day-ahead market.

\section{2) Assumption 2: timing of the day-ahead market}

As stated before, the operation will be made on an hourly basis for the next day. It means, for each of the 24 hours $(t=$ $1, \ldots, 24)$ of the next day, which is $\mathrm{d}+1$.

\section{3) Assumption 3: energy quantity demanded}

Demand is assumed to be infinite. In this case, a renewable energy operator sells as much energy quantity as he desire since the storage is used for time shift (arbitrage) grid application. This is also reasonable for an individual solar/wind farm since it supplies only a small fraction of the total electricity. It is yet considered a very small player on the market as a whole. Hence, the operator would not significantly affect the amount of supply. In reality, demand is usually forecasted by electricity producers. They must often anticipate demand curves.

\section{4) Assumption 4: transmission capacity}

The capacity of transmission will be assumed to be unlimited. This assumption can be realistic on the level of a small wind-farm operator. Otherwise, a maximum allowable commitment level will be needed.

\section{5) Assumption 5: power generation throughout an hour}

The power output of wind/solar farms is assumed to be constant throughout the hour. In reality, renewable energy farms generally produce fluctuating power.

\section{6) Assumption 6: operational capability of energy storage technologies}

All storage technologies are assumed to be capable of coming online instantaneously. They are also assumed to be operating at the same level of performance throughout the hour. In reality, for example, compressed air energy storage has a startup rates for about 7 minutes for an emergency start.

\section{B. Operation Algorthim}

The ultimate objective of this problem is to maximize the profit (the net present value) of renewable plants with storage device. This work would model this problem as an optimal hourly scheduling for twenty four hours spectrum. Yet, it will use optimal scheduling of charging and discharging of the energy storage system, grid power purchase, and generation.

The storage optimization problem is set up as a Non-linear programming (NLP) model. The optimization procedure will first solve the optimal storage dispatch given the farm production output, electricity prices, efficiency limitations, and taking into consideration the power and the energy constraints on the storage device. Then, from the obtained dispatch profile, renewable plant revenues are maximized given financial characteristics.

\section{1) Parameters: inputs/outputs}

The optimization model requires some inputs in order to provide optimal outputs. These include hourly plant generation, storage characteristics, and hourly market prices. The variable outputs include hourly energy storage dispatch profile and the plant total revenues.

The NLP Model has the following inputs and outputs:

2) Inputs

- $E_{\text {price }}(t)$ : Price of Electricity $(€ / \mathrm{MWh})$.

- $E_{\text {generated }}(t)$ :Energy Generation (MWh).

- $d$ : Storage Self-discharge Rate (\%).

- $\eta$ : Round Trip Efficiency (\%).

- $S E_{\text {limit }}:$ Storage Energy Limit (MWh).

- $S P_{\text {limit }}$ : Storage Power Limit (MW).

3) Outputs

- $E_{\text {discharged }}(t)$ : Energy discharged from storage (MWh).

- $\mathrm{E}_{\text {injected }}(t)$ : Energy injected directly to the grid (MWh).

- $E_{\text {stored }}(t)$ : Energy sent to storage (MWh).

- $S_{\text {level: }}$ Storage Level (MWh).

- Revenue: Total Revenues (€).

4) The revenue objective function is

$$
\max \left[\operatorname{Re} \text { venue }=\sum\left(E_{\text {injected }}(t)+E_{\text {discharged }}(t)\right) \times E_{\text {price }}(t)\right]
$$

where:

$\boldsymbol{t}$ : the hour within the optimization timeframe, $E_{\text {injected }}(t)$ : is the energy vector in hour $t$ that are injected directly to the grid, $E_{\text {discharged }}(t)$ : is a vector of energy values that are discharged from the storage, and $E_{\text {price }}(t)$ : is the price of electricity in hour t.

a) Energy generation constraint

The energy generated is either stored or injected to the grid. Therefore, the energy being injected can be related to the energy sent to storage in the following constraint:

$$
E_{\text {generated }}(t)=E_{\text {stored }}(t)+E_{\text {injected }}(t)
$$

\section{b) Energy storage equation}

The relationship between an energy storage level and the power that flows in/out of the storage is:

$$
S_{\text {level }}(t)=S_{\text {level }}(t-1) \times(1-\mathrm{d})+\left(E_{\text {stored }}(t) \times \eta\right)-E_{\text {discharged }}(t)
$$


The storage level at time $t$ is the amount of energy remaining in the storage device at $(\mathrm{t}-1)$ plus the power that has been added to the stored and minus the energy discharged. This energy storage equation takes into account the self-discharge rate and round-trip efficiency of the storage device.

\section{c) Energy storage system constraints}

The energy storage capacity and power limitations are as follows:

d) Power limit constraints

$$
\begin{gathered}
E_{\text {discharged }}(t) \leq S P_{\text {lim } i t} \\
E_{\text {stored }}(t) \leq S P_{\text {lim } i t}
\end{gathered}
$$

\section{e) Capacity limit constraint}

$$
S_{\text {level }}(t) \leq S E_{\text {limit }}(t)
$$

SE_Limit is the capacity limitation of the storage device in $\mathrm{MWh}$, and SP-Limit is the power

\section{f) Storage discharge}

The energy that is discharged from the storage cannot be more than the energy that is in the storage at that time. The following equation illustrates this constraint:

$$
E_{\text {discharged }}(t) \leq S_{\text {level }}(t)
$$

\section{g) Energy Storage Control}

$$
E_{\text {stored }}(t) \times E_{\text {dischaged }}(t)=0
$$

In general, the storage optimization model often includes a constraint that controls the operation of the storage which is "not to discharge energy and charge it at the same time". When storing energy and discharging it at the same time, energy is lost in the process because there is an efficiency sacrifice related to storing energy and discharging it. Since the model objective function is to maximize profit, it is more optimal to inject this energy rather than storing it and discharging it at the same time. Therefore, this restriction is logical. It has been tested with many different scenarios, and it has been confirmed that the optimal process is never to store and discharge energy at the same time.

\section{h) Positive bound constraints}

Another constraint on the power flow that is important to add is the positive sign. Therefore, the lower bound of each metric should be zero.

$$
\begin{gathered}
E_{\text {discharged }}(t) \geq 0 \\
E_{\text {injected }}(t) \geq 0 \\
E_{\text {stored }}(t) \geq 0 \\
S_{\text {level }} \geq 0
\end{gathered}
$$

This optimization model is evaluated using General Algebraic Modeling System (GAMS) software. Using GAMS, it was possible to calculate the maximum value of adding a storage device to a renewable energy system within a time-varying price market. This software was able to quickly solve for the optimal storage dispatch for a $24 \mathrm{~h}$ spectrum.

\section{Case Study}

To test the proposed optimal operation strategy of the hybrid system, a case study is performed on a wind farm. A wind farm in Spain was chosen to perform this study.

The data were obtained from Red Eléctrica de España, S.A. (REE) which aim is to ensure the correct operation of the Spanish Power System carrying out two main activities: The operation of the Spanish electrical power system and the transport on the high voltage power network [21].

April 25, 2014 was chosen for this case study. The day-ahead data of electricity prices are plotted in the following graph (see Fig. 1).

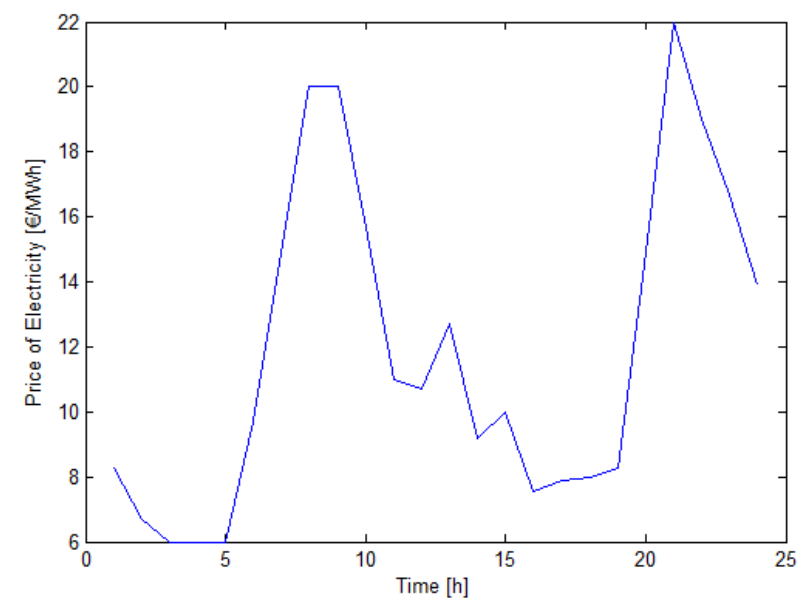

Fig. 1. Hourly energy prices for April 25.

The electricity prices are very low at night between $1 \mathrm{~h}$ to $6 \mathrm{~h}$ am, while they start to increase at $8 \mathrm{am}$. The peak price is achieved at $9 \mathrm{~h} \mathrm{pm}$. The Red Eléctrica de Espana Website provides also forecast of a wind farm generation. Time series for generation is presented below.

The energy generation of Peninsular wind farm fluctuates throughout the day due to the variation of the wind speed and other factors which include, for example, shutting down some wind turbines at night to avoid excess generation (see Fig. 2).

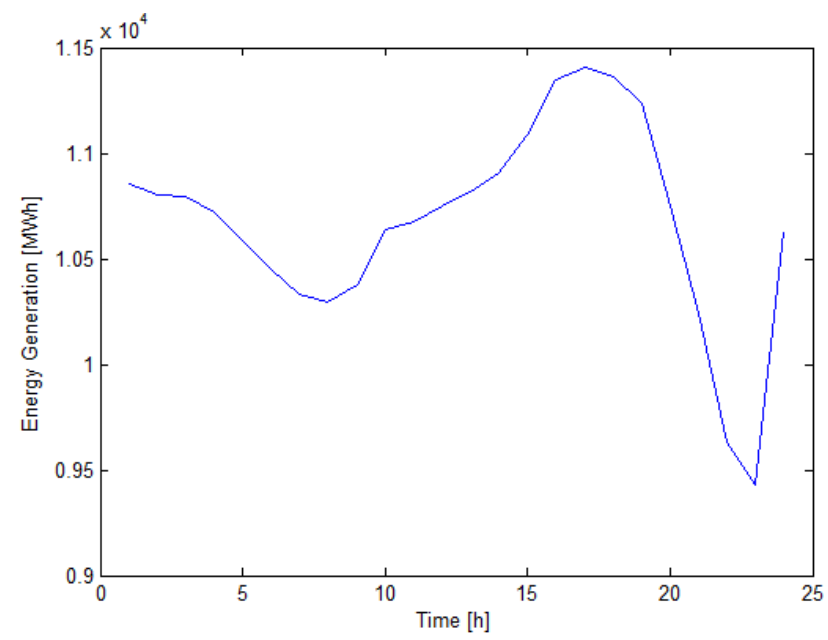

Fig. 2. Hourly generation for April 25.

The energy generation of Peninsular wind farm fluctuates throughout the day due to the variation of the wind speed and other factors which include, for example, shutting down some wind turbines at night to avoid excess generation.

The energy storage used in this study is pumped hydro 
which was chosen using ES-Select ${ }^{\mathrm{TM}}$ tool. An appropriate size of pumped hydro energy storage which could be used in this study has a power rating of $3000 \mathrm{MW}$ and a capacity of 5000 MWH. The round-trip efficiency of the storage is $70 \%$ and the self-discharge is negligible.

\section{Result and Analysis}

Results of the case study are presented in the following figures. As illustrated in Fig. 3 and Fig. 4, the energy storage system is charged at low price times, then it is kept on hold until the high price times occurs. At that time, the energy stored in ESS is released.

After discharging the energy when the prices reach the maximum, it again restores energy when the price drops in order to discharge it at higher price.

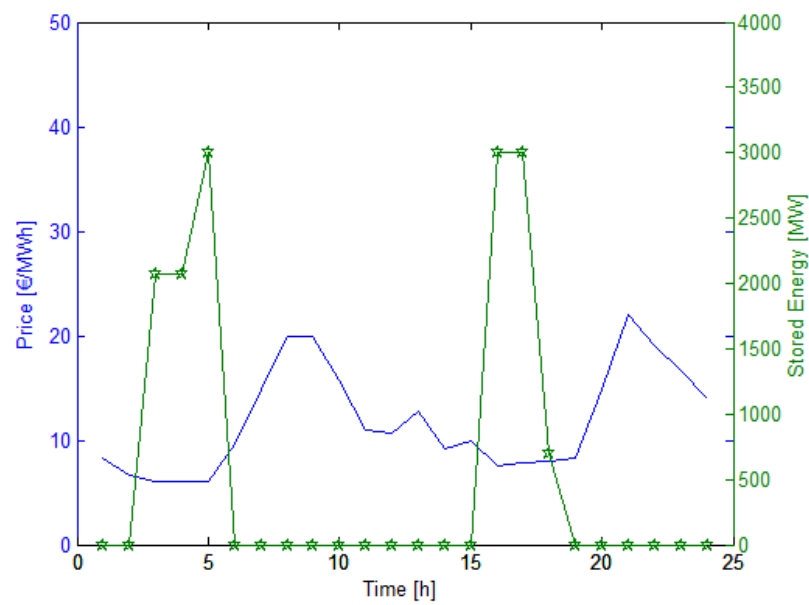

Fig. 3. time vs price vs stored energy.

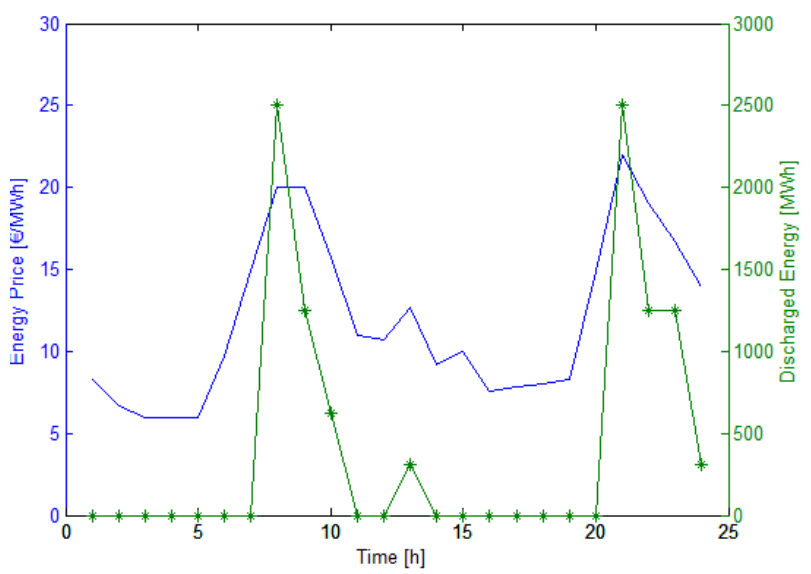

Fig. 4. Time vs price vs discharged energy.

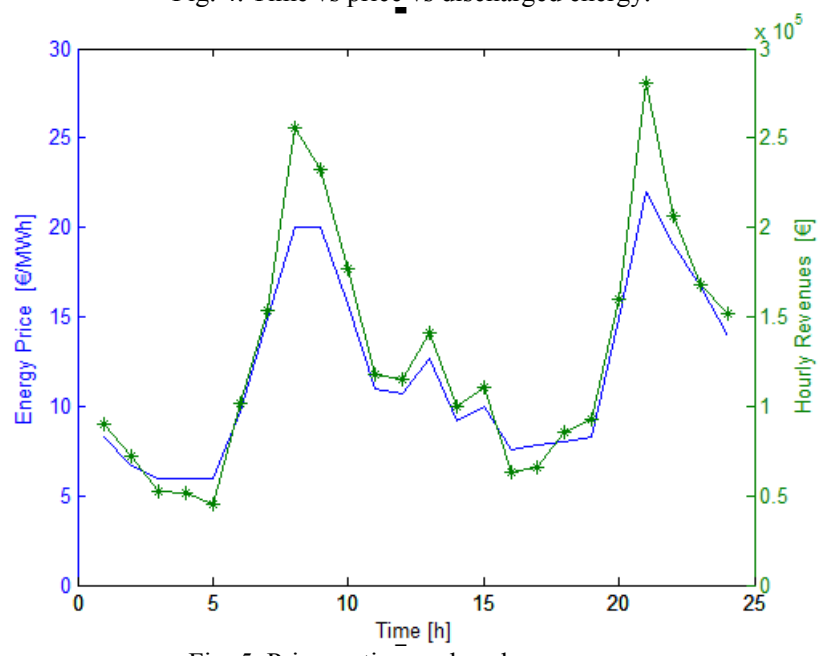

Fig. 5. Price vs time vs hourly revenues.
The system revenues increases by optimally scheduling the charging and discharging of the energy storage system, the discharging of ESS at higher priced hours enables the farm to sell energy when it is expensive. As illustrated in Fig. 5.

\begin{tabular}{|c|c|}
\hline Application & Daily Revenues (\$) \\
\hline $\begin{array}{l}\text { Wind Farm without Energy } \\
\text { Storage }\end{array}$ & $3,003,523.00$ \\
\hline $\begin{array}{l}\text { Wind Farm with Energy } \\
\text { Storage }\end{array}$ & $3,091,065.244$ \\
\hline Total Gain & $\begin{array}{l}3091065.244-3003523.00 \\
=\$ 87,542.05\end{array}$ \\
\hline
\end{tabular}

Without the use of energy storage system, the farm daily revenues would be equal to $\$ 3,003,523.00$. On the other hand, with the optimal use of ESS, the total daily revenues are equal to $\$ 3,091,065.244$. The daily economic gain is $\$ 87,542.244$ as illustrated in Table I.

To perform an economic analysis, the capital cost of the energy storage system should be estimated. The estimated capital cost of $3000 \mathrm{MW} / 5000 \mathrm{MWh}$ of Pumped Hydro Energy Storage is [22]:

$$
(2700 \times 3000)+(250 \times 5000)=\$ 9,350,000 .
$$

Therefore, the use of energy storage can be economical when it is used optimally. With the increasing penetration of renewable energy sources, ESS is becoming an important part of any grid. The optimal use of ESS can reduce system operational cost and can also provide the power system with more stability and flexibility.

\section{System SizING MODEL FOR LOAD LEVELLING APPLICATION}

\section{A. Storage Sizing Algorithm}

Proper matching of power generation and load profiles is one of the most prominent issue facing renewable energy farms. To solve this issue, energy storage may be used for load levelling application.

The goal of this section is to optimize the size of the storage system with respect to the net present cost (NPC), while meeting the service requirement. Various storage technologies have the advantage that their capacity is scalable. Therefore, a proper storage sizing is a much for renewable energy farms.

The storage sizing problem is set up as a linear and Non-linear programming (NLP) models as two different scenarios will be presented. The optimization procedure will first solve the optimal objective function given the farm generation, the load demand, the efficiency limitations, and taking into consideration the power and the energy constraints on the farm.

\section{1) Parameters: input/ output}

Both models require some inputs in order to provide optimal outputs.

2) Inputs

- $E_{\text {generated }(t)}$ : Energy Generation $(\mathrm{kWh})$.

- $d$ : Storage Self-discharge Rate (\%). 
- $\eta$ : Round Trip Efficiency (\%).

- Demand $(t)$ : hourly energy demand (kWh).

- Power $_{\text {cost }}$ : storage Power cost $(\$ / \mathrm{kW})$.

- Energy $_{\text {cost }}$ : Storage energy cost $(\$ / \mathrm{kWh})$.

3) Outputs

- $S_{\text {capacity }}$ : Storage energy capacity $(\mathrm{kWh})$

- $S_{\text {power }}$ : Storage Power rating $(\mathrm{kw})$

- $E_{\text {discharged }(t)}$ : Energy discharged from storage $(\mathrm{kWh})$.

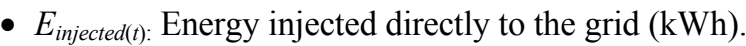

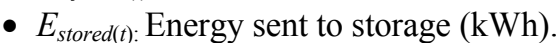

- $S_{\text {level: }}$ Storage Level (kWh).

- Cost: Objective function $(\$)$

The same assumptions used in the scheduling model are kept for the storage optimal sizing models. However, the assumption about energy demand is removed because in this case, the farm has to meet the demand.

The objective function for the system optimization is to minimize the total cost of the system while being able to meet the service requirement.

4) The cost objective function

$$
\operatorname{Min}\left[\begin{array}{l}
\text { Cost }=\left(S_{\text {capacity }} \times \text { Energy }_{\text {cost }}\right) \\
+\left(S_{\text {power }} \times \text { power }_{\text {cost }}\right)
\end{array}\right]
$$

In the sizing models, many of the constraints of the previous models have been keeps as they describe the proper functioning of energy storage. (These constraints will not be repeated here). New constraints related to the demand have been added since the system in this case should meet the service requirement.

a) The system power balance

This constraint makes sure that the load is always met, the storage is operated correctly and the generated energy is utilized properly. The system power balances at each time step, t:

$$
E_{\text {generated }}(t)+E_{\text {discharged }}(t)-E_{\text {stored }}(t)=\operatorname{demand}(t)
$$

\section{b) The demand constraint balance}

This constraint ensure that the demand is meet by injecting energy directly from the grid or discharging it from the energy storage when there is a shortage.

$$
E_{\text {disch arged }}(t) \times E_{\text {injected }}(t)=\operatorname{demand}(t)
$$

\section{c) Energy Storage Control}

$$
E_{\text {stored }}(t) \times E_{\text {disch arged }}(t)=0
$$

In this optimization study, the constraint of charging and discharging at the same time may be unnecessary because the aim of this study is to optimize the size of the storage system with respect to the net present cost (NPC), while meeting the service requirement. Therefore, after meeting the total load, the system may choose to shunt the excess energy for free rather than to store it. Hence, the resulting system will have the smallest size possible to meet the requirement.

In this case, two scenarios will be performed to verify the issue of shunting energy. The first scenario will include the restriction of charging and discharging at time, while the second one will allow the shunting of energy.

The optimization model of the second scenario is formulated as a linear programming algorithm as it contains only linear constraints. Both models are performed using (GAMS) software.

\section{B. Result and Analysis}

For both cases, the results show that the total load is met by the wind farm and the energy storage.

\section{1) First scenario}

When the demand is less than the generated energy, at 6 am, for example, a portion of the energy that is generated is injected directly to the grid while the excess energy is stored as shown in the results. In this case, the system does not discharge as it is restricted to charge and discharge at the same time. On the hand, when the demand is greater than the generated energy, at 12 am for example, the system discharge of the amount of energy that is needed to meet the service requirement. As illustrated in Fig. 6.

\section{2) Second scenario}

In this scenario, the total load is also meet while minimizing the size of the storage. At $6 \mathrm{am}$, the system injects only $47 \mathrm{MWh}$ and chooses to charge the storage with the remaining generated energy which is $36 \mathrm{MWh}$. At the same time, the storage discharged $16 \mathrm{MWh}$, to meet the required demand. In this case, the storage charge and discharge at the same time in an attempt to shunt energy. Hence, this scenario reduces the capacity of the storage while meeting the service requirement. As illustrated in Fig. 6.

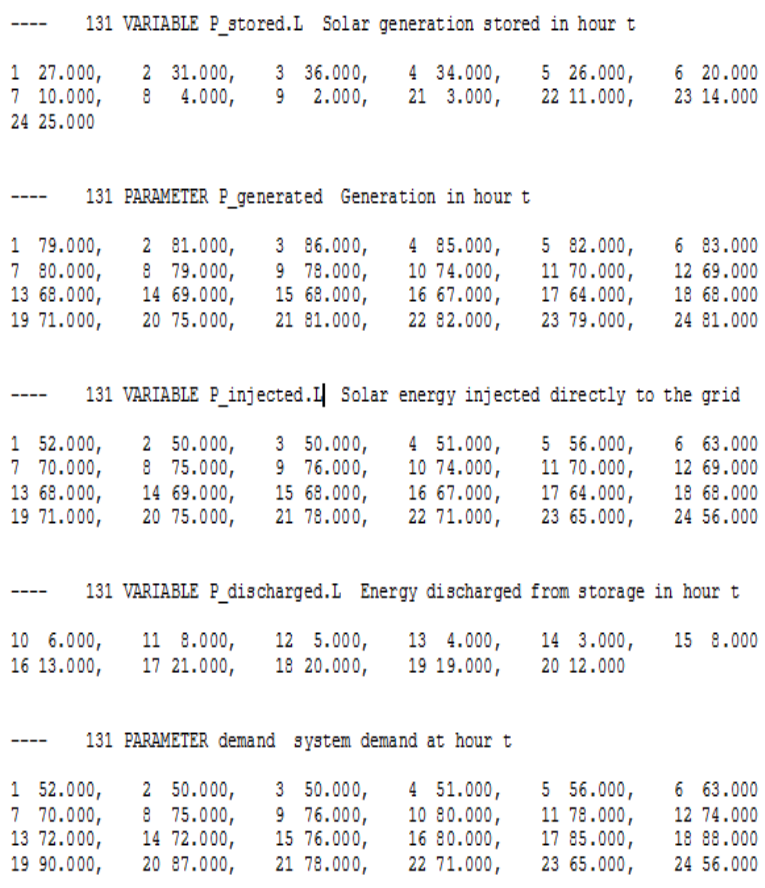

Fig. 6. Results of the first scenario model.

The results are of both models are the following:

a) Storage size of the first scenario

VARIABLE s_Capacity.L $=161.500$ capacity limit VARIABLE s_Power.L $=36.000$ Power rating

b) Storage size of the second scenario

VARIABLE s_Capacity.L $=146.500$ capacity limit 
VARIABLE s_Power.L $=36.000$ Power rating

c) The objective function of the first scenario

$\begin{array}{ccc}\text { LOWER } & \text { LEVEL } & \text { UPPER } \\ \text {-INF } & 33225.000 & + \text { INF }\end{array}$

--- objective -INF $33225.000 \quad$ +INF

d) The objective function of the second scenario

$\begin{array}{cccc} & \text { LOWER } & \text { LEVEL } & \text { UPPER } \\ \text {---- objective } & \text {-INF } & 30930.000 & + \text { INF }\end{array}$

Comparing the two scenarios, it is obvious that the second case results in a system that has the smallest size possible to meet the requirement. Since our objective function is to minimize the system cost, the second optimal sizing model (Fig. 7) provides the lower cost possible.

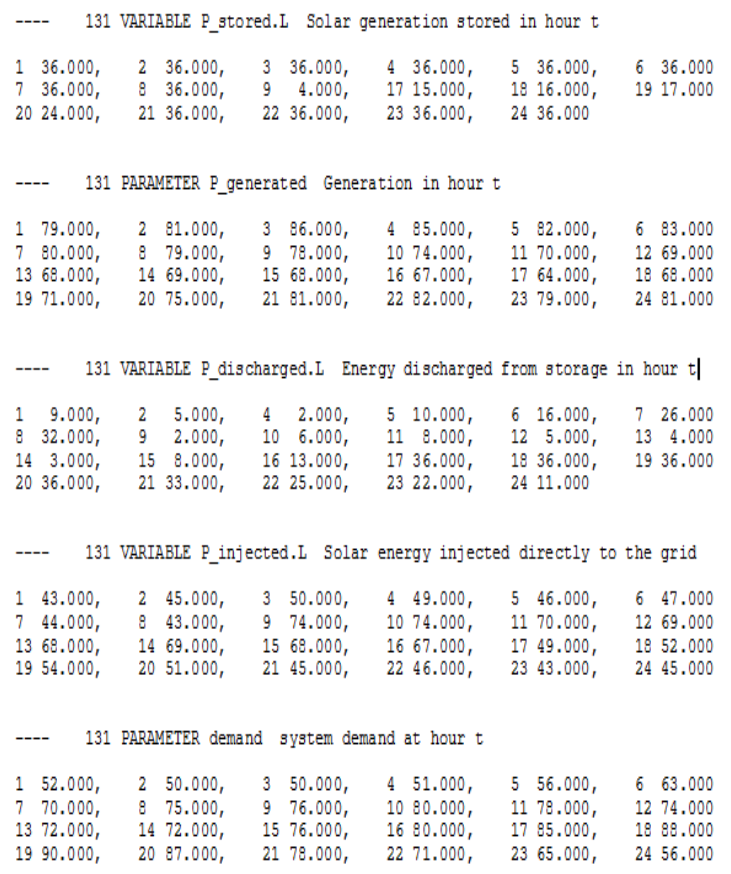

Fig. 7. Results of the second scenario model.

\section{CONCLUSION}

This paper presents methods to identify the optimum daily operational strategy and sizing of a storage system. The implementation of the optimal scheduling model taking into account the market price and operational restrictions of the hybrid energy system resulted in an economic gain of the wind farm. The effectiveness of this model was verified by a case study. Simulation outcomes showed that a proper scheduling of the charging and discharging of the energy storage enables the firm to take advantage of the energy price variation during the day, by charging during low prices and discharging when the energy prices are high.

Furthermore, the proposed methodology for optimizing the power rating and the capacity of an energy storage system enables the wind power farm to reduce the cost of the energy storage while meeting the demand.

\section{A. Future Work}

The development of energy storage is progressive. Therefore, it is crucial to update the storage parameters to reflect the actual market conditions. It is important to model accurate characteristics as much as possible.
The methodology used could be adapted to model other renewable energy plants such as solar photovoltaic or concentrated solar power coupled with thermal storage. In addition, other grid application would be used. Instead of central or bulk application, residential or commercial applications can be modeled using a similar methodology. Furthermore, other time frame and window would be used. The optimization horizon would be modeled for an entire year. Furthermore, the hourly basis would also be changed to half-hour in order to have more accurate results.

The modeling methodology could also be improved by taking into consideration more operational characteristics of the technologies used. For example, adding other control variables such as the charge/discharge cycle of the storage device. This would include other dimensions related to lifetime. However, the inclusion of new features will complicate the optimization model.

For the sizing model, future work would look at the optimum sizing the entire hybrid system. This would offer some insight related to new installed power plants.

\section{ACKNOWLEDGMENT}

"The research leading to these results has received funding from the European Union Seventh Framework Programme (FP7/2007-2013) under grant agreement no. 608593 (EuroSunMed)".

\section{REFERENCES}

[1] B. Lu and M. Shahidehpour, "Short-term scheduling of battery in a grid-connected PV/battery system," IEEE Trans. Power Syst, vol. 20, pp. 1053-1061, 2005.

[2] X. Y. Wang, D. M. Vilathgamuwa, and S. S. Choi, "Determination of battery storage capacity in energy buffer for wind farm," IEEE Trans. Power Syst, vol. 23, pp. 868-878. 2008.

[3] M. K. Marwali, H. Ma, S. M. Shahidehpour, and K. H. A. Rahman, "Short-term generation scheduling in photovoltaic-utility grid with battery storage," IEEE Trans. Power Syst, vol. 13, pp. 1057-1062, 1998.

[4] T. Y. Lee and N. Chen, "Optimal capacity of the battery energy storage system in a power system," IEEE Trans. Energy Convers., vol. 8, pp. 667-673. 1993.

[5] J. T. Alt, M. D. Anderson, and R. G. Jungst, "Assessment of utility side cost savings from battery energy storage," IEEE Trans. Power Syst., vol. 12, pp. 1112-1117, 1997.

[6] C. H. Lo and M. D. Anderson, "Economic dispatch and optimal sizing of battery energy storage systems in utility load-leveling operations," IEEE Trans. Power Syst, vol. 14, pp. 824-829, 1999.

[7] A. G. Bakirtzis and P. S. Dokopoulos, "Short term generation scheduling in a small autonomous system with unconventional energy sources," IEEE Trans. Power Syst., vol. 3, pp. 1230-1236, 1988.

[8] H. Yang, W. Zhou, L. Lu, and Z. Fang, "Optimal sizing method for stand-alone hybrid solar-wind system with LPSP technology by using genetic algorithm," Solar Energy, vol. 82, pp. 354-367, 2008.

[9] O. Ekren and B. Y. Ekren, "Size optimization of a PV/wind hybrid energy conversion system with battery storage using response surface methodology," Appl. Energy, vol. 85, pp. 1086-1101, 2008.

[10] S. A. Pourmousavi, M. H. Nehrir, C. M. Colson, and C. Wang, "Realtime energy management of a stand-alone hybrid wind-microturbine energy system using particle swarm optimization," IEEE Trans. Sustain. Energy, vol. 1, pp. 193-201, 2010.

[11] A. Roy, S. B. Kedare, and S. Bandyopadhyay, "Optimum sizing of wind-battery systems incorporating resource uncertainty," Appl. Energy, vol. 87, pp. 2712-2727, 2010.

[12] D.B. Nelson, M. H. Nehrir, and C. Wang, "Unit sizing and cost analysis of stand-alone hybrid wind/PV/fuel cell power generation systems," Renew. Energy, vol. 31, pp. 1641-1656, 2006.

[13] J. P. Barton and D. G. Infield, "A probabilistic method for calculating the usefulness of a store with finite energy capacity for smoothing 
electricity generation from wind and solar power," J. Power Sources, vol. 162, pp. 943-948, 2006.

[14] F. A. Chacra, P. Bastard, G. Fleury, and R. Clavreul, "Impact of energy storage costs on economical performance in a distribution substation," IEEE Trans. Power Syst, vol. 20, pp. 684-691, 2005

[15] M. Korpaas, A. T. Holen, and R. Hildrum, "Operation and sizing of energy storage for wind power plants in a market system," Int. J. Elect. Power Energy Syst, vol. 25, pp. 599-606, 2003.

[16] C. Brunetto and G. Tina, "Optimal hydrogen storage sizing for wind power plants in day ahead electricity market. Renew," Power Gener, vol. 1, pp. 220-226, 2007.

[17] S. Chakraborty, T. Senjyu, H. Toyama, A. Y. Saber, and T. Funabashi, "Determination methodology for optimizing the energy storage size for power system," IET Gener. Trans. Distrib, vol. 3, pp. 987-999, 2009.

[18] T. K. A. Brekken, A. Yokochi, A. V. Jouanne, Z. Z. Yen, H. M. Hapke, and D. A. Halamay, "Optimal energy storage sizing and control for wind power applications," IEEE Trans. Subst. Energy, vol. 2, pp. 69-77, 2011.

[19] H. Bludszuweit and J. A. D. Navarro, "A probabilistic method for energy storage sizing based on wind power forecast uncertainty," IEEE Trans. Power Syst., vol. 26, pp. 1651-1658, 2011.

[20] J. Li, W. Wei, and J. Xiang, "A simple sizing algorithm for stand-alone PV/wind/battery hybrid microgrids," Energies, vol. 5, pp. 5307-5323, 2012.

[21] Red Eléctrica de España. [Online]. Available: http://www.ree.es/en

[22] Electric Energy Storage Technology Options: A White Paper Primer on Applications, Costs, and Benefits, EPRI, Palo Alto, CA, 2010.

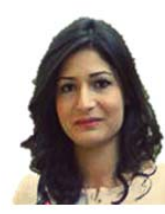

Asmae Berrada is currently working toward the combined bachelor/master degree in sustainable energy management at Al Akhawayn University. She was rewarded top honors at International Energy Symposium, organized by Helmholtz Zentrum Berlin and conducted Switzerland (Renewable energies: Photovoltaic, Solar Thermal \& Wind). She has also a first award in the 7th Engineering Design Competition in Al Akhawayn University

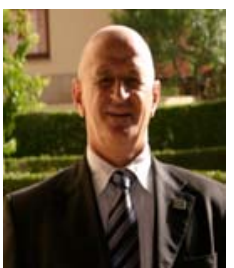

Loudiyi Khalid is a professor at Al Akhawayn University in Ifrane (AUI). He received several grants for research projects related to renewable energy at AUI (solar, wind, energy efficiency and energy storage). He served in designing different academic programs at AUI and at the Physics Department of Université Ibn Tofail in Kénitra. Amongst these: a "Master of science in sustainable energy management," the first of its type in Morocco. He coordinated the "Physics and Engineering" division at the School of Science and Engineering at AUI for the year 1995 and 1996.

Before joining AUI, he served as a professor of physics at "Faculté des Sciences, Université Ibn Tofail, Kénitra" Morocco (2009-2013) and a visiting assistant professor in Physics Department at Oklahoma State University (August 1988 - May 1989). 